\title{
Occupational injuries
}

O

ccupational injuries have been slowly declining in the past 50 years. It is not easy to

explain this declining trend because there are many simultaneous changes in working life. Increased attention to health and safety problems at work may probably be at least partly accountable for the positive changes. ${ }^{1}$ However, it is unclear whether the declining trend is still continuing or whether there is now a levelling off. ${ }^{2}$ It could well be that we have reached an injury rate level that is far more difficult to influence than the much higher rates in the past.

One of the problems in evaluating the effectiveness of measures to prevent occupational injuries is the relative lack of interest in conducting evaluation studies. Especially in industry, when rates are high or incidents have occurred, there is usually an immediate demand for preventive measures that does not mix well with rigorous evaluation to find out which ones are most effective. In general, work organizations are reluctant to experiment with health and safety measures. Interventions are usually the result of negotiations between stakeholders, and are often not based on scientific evidence.

The interest in gathering evidence on prevention of occupational diseases and injuries seems to be increasing. In the 1990s, several studies were published on the use of evidence for occupational health and safety interventions underpinning the need of a better evidence base. ${ }^{3}$ In 2000, the American Journal of Preventive Medicine published a series of articles systematically reviewing the evidence on a range of occupational health and safety interventions. Unfortunately, this initiative seemed to be unique and did not have any follow-up. In a recent study, we looked at the amount and sort of evidence available for occupational health and safety interventions in the major occupational health journals. We concluded that there was no reason for pessimism because the amount of evidence was comparable to other disciplines and at least half of it was of reasonable quality. Compared with studies carried out in the 1990s, we noted a positive trend in the quality and numbers of studies. ${ }^{4}$

Building on these efforts, it was a logical step for the Finnish Institute of Occupational Health to join the Cochrane Collaboration with an Occupational Health Field. The field was registered with the Cochrane Collaboration in May 2004. Its tasks are to support the production of systematic reviews and authors of systematic reviews, and to maintain a database of occupational health intervention studies. The database is freely available at http://cohf.fi. The studies are classified according to outcome and study design, which facilitates the search-for example, high-quality safety management studies. ${ }^{5}$ Even though sometimes occupational health and safety seem to be in different domains, we think they have much in common and should be regarded as belonging to one field of occupational health and safety.

Until now we have been able to produce and support reviews on varying topics such as interventions for the promotion of hearing protection and stress management in healthcare workers. ${ }^{67}$ Several protocols have been published-for example, on manual material-handling advice for prevention and treatment of back pain and interventions to improve occupational health in depressed people. ${ }^{89}$

However, there have been no reviews published in the Cochrane Library in the field of occupational injuries. Thanks to funding of the Australian Safety and Compensation Council, we have been able to start reviews in two important branches of industry from the point of view of occupational safety: the construction industry ${ }^{10}$ and the agricultural industry. ${ }^{11}$ The construction industry is an important economic sector all over the world, but at the same time one of the most dangerous, with injury rates 2.5 times that of the general workforce. ${ }^{12}$ Most of the injuries result from falling from heights or being struck by a falling or moving object. Stricter legislation has been one of the most common interventions to reduce these injuries, but it is unclear whether this has had a positive effect. It is therefore important to search systematically for evidence of effectiveness of such legislative interventions. To facilitate this, we organized an international project team with construction industry safety experts from all around the world to help identify important interventions in the field. Injuries are also very common in the agricultural sector and there is a pressing need to identify effective interventions in this setting.

Because of the particular difficulties of evaluation research in work organizations, we decided to include not only randomized controlled trials but also controlled before-after studies and interrupted time series. It will be a challenge to summarize results from these diverse study designs. The protocols have now been published in The Cochrane Library, and we will have the reviews ready by early $2007 .^{10} 11$

We hope that these are the first of a long list of reviews on occupational injuries. By doing so, we hope to overcome at least some of the barriers to progress in occupational injury prevention research noted by Stout and Linn. ${ }^{13}$ On our website, we maintain a wish list of interventions for which we think it is worthwhile to review the evidence of effectiveness. If you want to join or to pick a topic from the list, do not hesitate to contact us (jos.verbeek@ttl.fi).

For enquiries about the Cochrane Injuries Group, contact Katharine Ker (katharine.ker@lshtm. ac.uk) or visit http://www.cochrane-injuries.Ishtm.ac.uk.

Jos Verbeek

Finnish Institute of Occupational Health; jos.verbeek@ttl.f 


\section{REFERENCES}

1 Loomis D, Richardson DB, Bena JF, et al. Deindustrialisation and the long term decline in fatal occupational injuries. Occup Environ Med 2004;61:616-21.

2 Fabiano B, Curro F, Pastorino R. Occupational injuries in Italy: risk factors and long term trend (1951-98). Occup Environ Med 2001;58:330-8

3 Shannon HS, Robson LS, Guastello SJ. Methodological criteria for evaluating occupational safety intervention research. Saf Sci 1999;31:161-79.

4 Ruotsalainen JH, Verbeek JH, Salmi JA, et al. Evidence on the effectiveness of occupational health interventions. Am J Ind Med 2006;49:865-72.

5 Verbeek J, Husman K, van DF, et al. Building an evidence base for occupational health interventions. Scand J Work Environ Health 2004;30:164-70.

6 El Dib RP, Verbeek J, Atallah AN, et al. Interventions to promote the wearing of hearing protection. Cochrane Database Syst Rev 2006;(2):CD005234.

7 Marine A, Ruotsalainen J, Serra C, et al. Preventing occupational stress in healthcare workers. Cochrane Database Syst Rev 2006;(4):CD002892

8 Martimo K, Verbeek J, Karppinen J, et al. Manual material handling advice and assistive devices for preventing and treating back pain in workers (Protocol). Cochrane Database Syst Rev 2006;(2):CD005958.

9 Nieuwenhuijsen K, Verhoeven A, Bultmann U, et al. Interventions to improve occupational health in depressed people (Protocol). Cochrane Database Syst Rev 2006;(4):CD006237.

10 van der Molen H, Lehtola M, Lappalainen J, et al. Interventions for preventing injuries in construction industry (protocol). Cochrane Database Syst Rev 2006;(4):CD006251.

11 Rautiainen RH, Lehtola M, Day L, et al. Interventions for preventing injuries in the agricultural industry (Protocol). Cochrane Database Syst Rev 2007;(1):CD006398.

12 Arndt V, Rothenbacher D, Daniel U, et al. Construction work and risk of occupational disability: a ten year follow up of 14,474 male workers. Occup Environ Med 2005;62:559-66.

13 Stout NA, Linn HI. Occupational injury prevention research: progress and priorities. Inj Prev 2002;8(Suppl 4):IV9-14.

\section{International Forum on Quality \& Safety in Health Care}

18-20 April 2007

Palau de Congressos, Barcelona

Registration now open

- Book by 23 February 2007 and save up to $£ 60$ on the 3-day delegate fee

- Join us at the premier international event for those dedicated to improving quality and safety in health care

- Speakers include: Donald Berwick, Sir John Oldham, Lucien Leape, Richard Smith, Helen Bevan, Lloyd Provost and Rosa Sunol

- For more information and to book online please visit: www.quality.bmipg.com 